\section{THE CULTURE OF THE HUAYAO DAI AND ITS PROSPECTS - COMPARA- TIVE RESEARCH ON THE CULTURAL CHAR- ACTERISTICS OF THE DAI PEOPLES LIVING IN THE UPPER REACHES OF THE RED RIVER}

\section{Zheng Xiaoyun ${ }^{1}$}

\begin{abstract}
Tai people, formally known as of Dai nationality in China, number 1.1 million. One of the greatest concentrated region of Dai people in China is the reaches of the Red River, called the Yuan Jiang River. Here their ethnic culture is particularly to be found. The Dai people of the Red River number about 150,000 which is $13 \%$ of the total Dai population of China. Furthermore about half of those 150,000 live in Xin Ping and Yuan Jiang counties, on the upper reaches of the river. Traditionally, the Dai people of the upper Red River were called Huayao Dai, or "Flower Waist" Dai, because of the long and colourful waistband which is an ethnic symbol of the women. The Huayao Dai comprise various sub-ethnic groups, such as Dai Ya, Dai Ka and Dai Saai in Xin Ping county, and Dai Ya, Dai Zhong, Dai Zhang and Dai De in Yuan Jiang county. The Huayao Dai have various cultural features which distinguish them from other Dai. 1) Ethnic finery, such
\end{abstract}

\footnotetext{
'Deputy Director and Professor, Institute for Ethnology, Yunnan Academy of Social Sciences, Kunming, Yunnan, China.
}

as the women's waistband, which has a varied cultural significance. 2) Adobe houses, quite different from those of the Dai people outside this region. 3) Festivals, many of which are shared with the Han, but have their own features. The Flower Fair Festival is Huayao Dai. 4) An Animist religion, similar to that of other Dai, but with certain distinguishing features.

Changes in contemporary Huayao Dai culture are discussed in this paper. Although traditional forms of dress and housing, tooth dying, tattooing, ethnic language, festivals and traditional religion are preserved, there have been changes since the 1950 s, due to modern education and health care, as well as greater contacts with other cultures. Tourism has expanded rapidly, as outsiders become attracted by the colourful culture, and this has led to greater mobility among the Huayao Dai people. There have been economic changes also. The goal of agricultural production has changed from fulfilling local needs to meeting the needs of the market place. Many cash crops such as sugar cane and tropical fruits and vegetables are now grown. This has led to increasing income and an improved standard of living, which also has great impact on Huayao Dai culture.

\section{Introduction}

The population of the Dai Nationality in China is more than 1.1 million. The Dai people mainly live in the south of Yunnan Province. Most of them live in the Xishuangbanna Dai Autonomous Prefecture, Dehong Jingpo Autonomous Prefecture and Lincang Prefecture. Dai settlements are concentrated in some particular areas, but some groups have 
migrated and settled along big rivers, such as in the Me-Kong Valley and the Red River Valley in China. The Red River' Valley is a very important area because Dai people, who make this area culturally unique, densely populate it. Therefore research on the Dai people's culture in this area will be significantly valuable, but until today research on the essence of the Huayao Dai peoples' culture and knowledge of the culture are rather insufficient. In this article, the particular essence of the Huayao Dai people's culture will be studied and evaluated, and its prospects will be predicted.

The source of the Red River is Mao Caoshao in Dali Bai Nationality Autonomous Prefecture. From here the river flows southeastward through 12 counties, covering 692 kilometers in China: Weishan, Nanjian, Nanhua, Chuxiong, Xinping, Yuanjiang, Honghe, Yuanyang, Gejiu, Mengzi, Jinping, and Hekou then into Vietnam. It is called the Yuan Jiang River in China and the Red River in Vietnam. (1)

Huayao Dai is a conventional name given by other nationalities to the Dai people living in the Red River Valley areas. The name originated from the special long colorful belt worn by Dai women living in these areas.

The ethnic Dai living along the Red River Valley in China number 150,000 which is about thirteen percent of the total Dai Nationality's population in China. More than 50 percent of them live in the upper reaches of the Red River called Xinping and Yuanjiang Counties. This area is located in the central section of the famous Yunnan Ailao Mountains, a geographical area of mountains and rivers, which is the cultural center of the local Dai people.
Due to the long history of immigration and social closeness, the Dai People in the Red River Valley have formed a variety of ethnic sub groups who call themselves differently. In the upper reaches of Xinping county, there are 3 ethnic sub groups who call themselves Daika, Daisaai and Daiya. There are 7 Dai subgroups in Yuanjiang County: the Dai, Daizhong, Daika, Daiya, Dailang, Daide and Daizhang.

In the middle and lower reaches of the Red River, there are the Daiduan, Daiyu, Dailu, Dailang, Dailiang and so on. Among them the Daiduan and Dailu are culturally different from the other Dai ethnic subgroups. For example, they like to insert artificial gold teeth, and their houses are like those in Xishuangbanna and Dehong which are railing style structures, while other local Dai people like to dye their teeth black and live in two or three-floor adobes made of earth with flat roofs. Although most of the Dai ethnic subgroups in the Red River valley call themselves differently, thry possess roughly the same cultural characteristics, and most of them are called the Huayao Dai people. (2)

\section{The uniqueness of the Huayao Dai people in Dai ethnic peoples' culture.}

The Dai people have their own common cultural characteristics wherever they live, but owing to the diversity caused by their historical development (such as immigration and mixing with other ethnic groups), and geographically different environment, Dai people living in different areas have formed different ethnic subgroups and geographically varied cultural features. Today the Dai people in the Red River Valley area also 
possess both characteristics common to other Dai and their own cultural character.

First let's take a look at 5 common cultural characteristics shared by the Red River Valley's Dai people and the other areas' Dai people:

a) One of the typical cultural characteristics is the preference for living in flat valley areas. The best location for Dai people is a place facing water in front of mountains. Both the Dai people in the Red River Valley and the Dai people in Xishaungbanna and Dehong areas hold this idea which has made them rather different from the other nationalities living in the mountain regions in their production methods and way of living.

b) Dai people engage in agriculture. From ancient times rice has been the Dai people's major agricultural product wherever they live. The Red River Valley's Dai People also live by growing rice, and like other regions' Dai people they eat glutinous rice. However, recently in order to increase production of other grain crops to meet market demands and their own grain consumption, the production of glutinous rice has gradually decreased.

c) Teeth dyeing and tattooing are Dai people's most ancient customs, having been recorded in a variety of historical literatures as Dai people's typical features. Dyeing teeth black is popular with the Huayao Dai women: they mix a kind of wild grass called smelly vine berry and niter, and then after mincing the mixture, they put it on palm leaves, and before going to bed, they cover the front of their teeth with the mixture. A couple of days later, the front of their teeth will turn black. Then the teeth will be fin- ished with wood tar until they become . shiny which is a token of the Huayao Dai women's beauty. Tattooing is done on the back of the Haoyao Dai women's hands. The tattoo patterns are usually flowers and animals.

d) Common Language. Since the Red River Dai peoples and other regions' Dai peoples belong to the same linguistic branch--the Dai linguistic branch, there are the same common basic elements in their languages. However, due to influences in the different regions and subgroups, their languages bear some distinct characteristics of individual Dai ethnic subgroups and their dialects. Even among the Red River Valley's Dai People, there are some linguistic differences among the various subgroups. For instance, there are 3 Dai ethnic subgroups who can communicate with each other in Xinping County, but their ways of expression and tonal systems are different from each other.

e) What a nationality calls itself is a reflection of its sense of identity. Even though Dai people in the Red River Valley are divided into different ethnic subgroups like other regions' Dai People, they all put the Chinese character "Dai" before the names of their subgroups. This conventional way of naming has existed since ancient times and has been the evidence showing that various Dai subgroups' unanimously identify themselves as an integrated Dai nationality. This phenomenon is also a characteristic of all the Dai peoples living in the whole of Yunnan Province.

The 5 features mentioned above are the major aspects of the common cultural characteristics of the Dai nationality. As we can see, the Red River Valley's Dai people share common cultural charac- 
ters with other Dai groups living in other regions.

Since Dai people live in different areas, they have also formed their own particular cultural characteristics. The Huayao Dai people have also formed many of their own distinctive cultural characteristics. Only after recognizing these differences, can we be fully aware of the cultural value of the Huayao Dai in the Red River Valley.

We will discuss five aspects of the Huayao Dai people's cultural differences:

1) The culture of costume. The reason why a majority of the Red River Dai people are called Huayao Dai is that Huayao Dai women habitually wear colorful long cloth belts around their waists. The Dai women in Xishuangbanna and Dehong also wear belts but they wear silver belts.

The second feature of the costume is that the Red River Valley's Huayao Dai decorate their costume with silver. A set of the silver ornaments for one Huayao Dai woman often weighs 4 or 5 kilos, which is very unique and special among the Dai people.

The third feature is the wide-brimmed bamboo hat commonly used by the Dai people in the Red River Valley. Although other Dai women use a hat to shield the sunlight, they prefer wearing a large turban. The Huayao Dai women not only regard the hat as an inseparable part of their costume but also as a symbol of their own ethnic subgroup's fashion.

2) The culture of housing. The housing style of the Huayao Dai living in the upper reaches of the Red River is remarkably different from the style of other regions. They live in an adobe house with a flat roof that usually has two floors. They live on the upper floor with a wide balcony that can be a resting place, a suntrap space, or a workshop for making farm tools, pottery, earthenware and so on. The lower floor can be a kitchen, a guestroom, or a storehouse and so on. The Dai houses along the lower reaches of the Red River are usually one-floor houses, whereas most of the Dai people in Yunnan Province live in a kind of railing-styled two-floor house mainly made of bamboo and wood. According to the records in different historical periods, the railingstyled house is a very important cultural characteristic of the Dai people in general.

3) Marriage and family. The Huayao Dai people living in the upper reaches of the Red River can freely choose to marry anyone. Historically the Dai people in this area live in a warm valley, where young people fall in love and get married comparatively early. When they reach the age of sixteen or seventeen, they can meet and choose their future mate various festivals, such as the typical flower fair in January. On market days they get to know each other, fall in love and exchange presents. If everything is all right, they get engaged. The new couple of the Huayao Dai should live with the groom's family, but after the wedding the bride returns to her own family until she is pregnant and moves to her husband's family before the birth of the new baby. While she stays with her own family, the groom can visit his wife now and then or on festival occasions. When the new baby grows up, the parents can consider living separately from the husband's parents. The hus- 
band and wife are equal. They both share family obligations and rights. Traditionally the husband and the wife have separate roles and functions both in farming and social life. If there are troubles in the marriage, divorce is a way out. A divorce is up the couple's own free will, and the procedures for divorce are very simple. Once the husband and the wife live separately, they can be considered divorced.

In Xishuangbanna, young Dai people can also choose their husbands and wives freely, and after the wedding, the groom should go to live with the bride's family for about 3 years before the couple can live separately from the bride's family. In Dehong Prefecture, arranged marriage is very popular. Marriages should be approved by the parents. Without parents' permission the marriage is impossible. After the wedding the bride should live with the groom's family, and divorce is restricted.

In Lincang Prefecture, which is between Xishuangbanna and Dehong, the Dai people's marriage customs are something between those of these two areas. Sometimes marriage is decided by the couple, and sometimes it is arranged. In some cases the new couple live with the groom's family, while in other cases they live with the bride's. Later, they live separately from their parents.

4) Religious belief.The Huayao Dai people as well as other regions' Dai people believe in a kind of animism which advocates that all things in the world are endowed with spirits and souls. They believe that rivers, mountains, woods and crops all embody individual spirits; therefore primitive worship of and sacrifice to various spirits are practised. Before spring ploughing, there is a sacrifice ceremony to pray to the divine spirits for a bumper harvest, which is a big annual event. After a bumper crop, they also pray to thank the spirit. Before going hunting in the mountains they pray for good hunting and after it, they pray to thank the spirit.

There is a big dragon tree in every village, which is the center of the village. Every year the grandest sacrifice is held to worship the tree. Every spring all the villagers kill pigs and cows to offer to the dragon under the tree and ask for good weather and abundant harvests. When somebody is ill, it is believed to be caused by devils and sacrifices to drive off the devils are held.

The Dai people in the Red River Valley do not believe in Buddhism, which makes them different from the Dai people in other regions who believe in Buddhism of the southern Hinayana sect. Buddhism has been fused into Dai culture and become an inseparable part of it. For example, it is customary that a man should become a Buddhist monk for some time during his lifetime, and in social life human actions and activities Buddhist teachings are observed. The ways of thinking are also influenced by Buddhist ethics, which emphasizes the present life and at the same time offers hope for the next life. Buddhist scripture, arts, song and dance, festivals and so on have all become part of the Dai's culture. This difference in beliefs has caused remarkable cultural differences between these two groups of Dai peoples in their ways of thinking, social behaviors, daily life, and arts.

5) Festivals: The festivals celebrated by the Red River Valley's Dai people are strikingly different from the other regions' Dai festivals since most of the 
Dai people living outside the Red River Valley have been influenced by Buddhist culture. The latter's festivals are generally originated from Buddhist festivals. For example, they celebrate the Dai New Year's Day, which is called the water-sprinkling festival by other nationalities. They also celebrate other festivals related to Buddhism such as the Buddhist Fast at the beginning of July, called the closed door festival, and the open door festival at the end of the fast.

In contrast, influenced by Han culture, the Huayao Dai people's major festivals are the same as the Han's such as the spring festival, the dragon boat festival, the mid-autumn festival and so on. The Huayao Dai people's festivals have also developed many local features and flavors. For instance, during the spring festival, local Huayao Dai people hold a special flower fair. On this special occasion, the young Huayao Dai people make friends and find future mates. They also dress in their special subgroup's costume to show their own ethnic beauty. The flower fair is also a very important local trade fair. The Huayao Dai's festival culture is strikingly different from other Dai people's. This reflects the extent of influence of different regions on cultures. The Red River Valley Dai people are influenced by Han culture while other regions' Dai people are influenced by Buddhist culture.

\section{The Huayao Dai people's culture in the social transition.}

Today in China the social economy and culture are developing rapidly and have stimulated the fast cultural transition of every nationality. Ethnic society has changed from closed to open. The traditional economic structure of various industries has been continuously regulated; therefore, outside culture has made a great impact on every traditional culture. For minority groups living in China, this social change is unprecedented; however, the influences of the impact on the ethnic culture are different according to every nationality's historical and cultural traditions, environment, degree of contact with the outside world, and the population.

In this process of great change, Dai people's culture is also subject to unavoidable transition. Understanding the rules of this transition is very important for the protection and preservation of the ethnic minority's culture. The following discussion will deal with the situation of the Huayao Dai people's culture during this modern social transition.

1) Today, the traditional culture of the Red River Valley has been well preserved. Today if you come to the major Huayao Dai people's living areas, such as Xin ping and Yuan jiang, you can still taste a strong flavor of Dai ethnic tradition. Here some observations of typical cultural elements.

Traditional Costume: whether in their homes or in the street on a special occasion you can see most Huayao Dai women with their traditional widebrimmed bamboo hats on their heads and the floral bamboo baskets hung around their waists. They will dress in colorful traditional costumes with shining silver decorations. Young people, however, prefer wearing clothes bought from shops, because the traditional ethnic costume is too complicated to make. Only on special occasions, such as festival or holiday, can you see the young Huayao Dai people in their traditional costumes. 
Housing: Today's Huayao Dai people still preserve their traditional adobe houses; however, some richer families have built new houses with traditional structure and conventional layout. From this, we can see that the traditional style of construction and housing has settled in Dai people's culture.

Teeth dyeing and tattooing: today most of the middle-aged Huayao Dai people especially the women still dye their teeth and have tattoos, and many young people follow suit. This phenomenon reflects the fact that this very important custom, which is different from other people's customs has been passed down from generation to generation as a local Dai tradition. Chewing betel nut, which is a custom closely related to teeth dyeing, has also been kept as a pastime of local people. Now this custom is popular with young people. When guests step in a Dai house, the hospitable Dai people entertain them with betel nuts.

Language: in recent years, many people especially young people attend school and even work outside the Dai region. They can speak standard Chinese, but the ethnic Dai Language is still the major language of the Huayao Dai People.

Festivals: traditional festivals are still celebrated. The Spring Festival, the Dragon Boat Festival, the Mid-autumn Festival and so on are also local Huayao Dai people's traditional festivals, but the most significant thing is that they have retained and even developed their own unique ways to celebrate these originally Han festivals. A typical example of this is that during the spring festival, the Huayao Dai people's flower fair has become more and more flourishing and grand. Interrupted for 40 years, the Mosha township flower fair was re- stored in 1991 and has become so popular that it is now the most important annual festival to the local Huayao Dai people.

Religion: Today's Huayao Dai people still hold the animistic ceremonies mainly to sacrifice to Mother Nature. Every year there are two major sacrificial ceremonies to the dragon. These animistic sacrifices remind us of the relationship between humankind and Mother Nature. They express man's good wishes for a bumper harvest and happiness. In animistic the conception that gods and ghosts control birth, aging, illness and death is fading away. Most young people do not believe in the mentioned conception. They take a scientific approach in their view of birth, aging, illness and death. It is necessary to point out that in the upper reaches of the Red River, these religious sacrifices to nature are intergrated in the culture of the Dai people in all areas. However, in other Dai people's areas especially the areas of those Dai people who believe in Buddhism, sacrifice to nature are not as equally observed.

The above-mentioned facts are some of the typical Huayao Dai's important cultural elements. In fact, in their social life many more traditional cultural elements are preserved. Today the Huayao Dai people are still imbued with their own unique traditional culture handed down from generation to generation.

2) Great changes in economic life: the Huayao Dai people live in a subtropical valley. From ancient times they have lived mainly on rice growing. Other agricultural products are sideline products. In fact, rice growing is the important base of the Huayao Dai people's social culture. Their knowledge of nature in- 
culture. Their knowledge of nature including the use of land and water resources, the growing of farm products, their various agricultural sacrifices to the divine for an abundant harvest as well as their daily farm work are all associated with rice growing, which is their vital means to survive. This kind of single economic structure of production had been sustained until the mid1980s. After enforcement of the policy of individual responsibility for agricultural production, and the open door policy, the industrial structure in Huayao Dai regions has changed tremendously. The changes include the development of a variety of industries and the transformation from a self-supporting economy to one of meeting market needs. Since the Huayao Dai people live in a subtropical valley which is suitable for growing various subtropical farm and economic products, with the help of the local government and under the condition of maintaining rice growing in this area, they have actively developed production of tropical fruits and vegetables, such as sugar cane, lychees, bananas, mangoes and so on. Some local governments have also helped the minority nationalities by introducing some excellent foreign species, such as foreign lychees, Taiwan purple dates and fast-maturing grapes. In order to develop vegetable planting activities at the same time, they take advantage of the warm local climate to plant fast-maturing winter vegetables in large areas, including beans, melons, peppers, eggplants, cucumbers, sugar beets and so on. During the winter season these products enjoy increasing demand and are sold not only in Yunnan but also in other provinces.

3) In the modern social transition, the Huayao Dai people's culture has digested a large quantity of modern ele- ments. With the transformation and the opening of their society, and by means of educational news media, social exchange and so on, outside culture is being introduced into Huayao Dai areas where people have digested many elements of other cultures and integrated them with their own traditional culture. For example, the young generation of Huayao Dai people have received elementary or high school education and become a new well-educated generation. They can speak standard Chinese and write Han characters. Even in the abovementioned Nanjian village, there are five high school graduates and 21 middle school graduates. The education level of this village is the same as that of the Xishuangbanna and Dehong regions.

There are many aspects in Huayao Dai people's culture which have been adapted to modern society. For example, the young people have the freedom and right to choose their future mates. In family life, husband and wife are equal. A woman can manage big events and financial affairs in her family. These good traditions have played an active role in the efforts of family planning, because woman can make decisions on the birth of a child. Today, it is well known that family planning policy is smoothly carried out among Dai people. The majority of Dai families have observed the family planning regulations by having one or two children.Very few families have more than one or two children. Another example is that while engaging in production and following the regulations of the production structure, Dai people have strengthened their awareness of the commodity economy and learned new production techniques, which has laid the basis for future development. In the process of today's development, the cul- 
ture of the Huayao Dai people can be mixed with modern civilization so smoothly that it can be well adapted to the development of modernization. This is a very significant feature of the Huayao Dai people's culture in the process of its new development.

\section{The modern connotation of the Huayao Dai people's cul- ture and its prospects}

In my opinion, the modern connotation of the Huayao Dai people's culture includes the following aspects.

a) The culture of the Huayao Dai people is a type of costume culture. The symbolic element in the Huayao Dai people is their costume. It is an important mark of the difference between the Huayao Dai people and other nationalities, and even annoy Dai ethnic subgroups. The name of the Huayao Dai people obviously originated from its costume. The Huayao Dai people's costume culture has important cultural connotation and consists of diverse elements such as the wide-brimmed bamboo hat, blouses with silver decorations, small floral bamboo basket and so on. The different subgroups also have their own styles. Furthermore, the Huayao Dai's costume bears rich cultural connotation which has been closely related to people's work skill, the division of labor between men and women, ways of living, and so on. For instance, in addition to normal farm work, the making of the costume is done by women and is a very important task for women. From this process, more culture has been generated. The ability to make a fine costume is a standard for measuring women's gifts and skills. The costume making site is also a place for the men and women to get together.
Hence in respect of its making, style, symbolic features and so on, the Huayao Dai's costume has rich connotation, which is most typical in its traditional ethnic culture.

b) The Huayao Dai culture is an original culture. It has not been influenced by Buddhism. Although we can not verify the history of the Dai people's immigration along the Red River, Huayao Dai culture today is most probable the reflection of the most ancient Dai people's cultural history. The ancient customs such as teeth dyeing, tattooing, activities of worship to Mother Nature are still retained in Huayao Dai culture today. They are practised in everyday life.

c) Huayao Dai culture reflects the harmonious relations between man and nature. From ancient times, Dai people have settled in the flat land in the river valleys, and rice growing is their most important agricultural production. Therefore, Dai people set great value on water resources. The preservation of water resources and protection of the environment are the very important traditional common sense of the Dai people. They have a tradition of planting large areas of fruit trees and other economic forests, and have built up an environment of beautiful rural scenery for living. This is a very unique feature of Dai areas. Today everyone who comes to visit the Dai people's living areas will be greatly amazed and have to admire the beautiful rural scenery. They perhaps do not realize that all this beauty shows the sense of cultural value observed by the people, and conservation of the environment. Because of theirs traditional cultural value, there is a better ecological environment in Dai regions which has formed a cultural atmosphere of har- 
monious relations between man and nature. Today's Huayao Dai culture typically reflects and symbolizes this sense of cultural value.

d) The culture of the Huayao Dai people can adapt to modern development. In the process of development, Huayao Dai culture has no contradiction to modern society. Conversely, it can mix with modern society, and in the process of modern development, it has introduced and digested many excellent elements of outside culture, such as education, science and technology, medicine, health care, the sense of a civilized life style, and so on. There are also many aspects in tradition Huayao Dai culture which are valuable in modern development. They include the harmonious relationship between man and nature, social harmony, the equality of men and women in their family life, the freedom to marry, colorful ethnic culture and so on. Therefore, today's Huayao Dai culture is a kind of composed culture based on its own ethnic cultural origins mixed with modern culture. (3) Like all other Dai cultures, the Huayao Dai culture is now well preserved, inherited, and at the same time, smoothly developed.

In view of the four aspects above, we can conclude that Huayao Dai culture is characterized by distinct ethnic cultural features as well as elements adapted to modern culture. It can, therefore, serve as a unique model for other ethnic groups.

\section{Notes:}

(1) "The Development and Use of Water Resources in Yunnan Province" by $\mathrm{Li}$ Mongrong et al. 1983.

(2) There are also some Huayao Dai people living in the areas other than the Red River
Valley area. For example, in Xiaomengyang in Xishuangbanna, there is a Huayao Dai village. The villagers immigrated to Xishuangbanna from Mosa in Xinping County more than one hundred years ago.

(3) Refer to "The Dai Culture in Social Tradition - Anthropological Research in a Dai Village in Xishuangbanna" by Zheng Xiaoyun in the "China Social Science Journal" issue No. 5, 1997.

\section{References}

The County Annals Office of Xinping Yi and Dai Autonomous County (eds.). 1986. A Brief Introduction of Xinping Yi and Dai Autonomous County. Yunnan Minority Publishing House: Kunming.

The Minority's Affairs Committee of Yuanyang Hani and Yi Autonomous County. (eds.). 1999. The Ethnography of the Yuanyang Hani and Yi Autonomous County. The Press of Yunnan University: Kunming.

The Office of The Ethnography of the Honghe Hani and Yi Autonomous Prefecture (eds.). 1998. Ethnography of the Honghe Hani and Yi Autonomous Prefecture. The Press of Yunnan University: Kunming.

The People's Politic Consulting Committee of Xinping Yi and Dai Autonomous County (eds.). Selection of the Cultural and Historical Materials about Xinping Yi and Dai Autonomous County. Volume 10 (2000).

Wang Gouxian. 2000. Investigation into the Ecological and Cultural Resources in Nanjian Village of Xinping County. (Unpublished Report). 